\title{
Mucormycosis and Candida Infections in Patients of COVID- 19 Pneumonia: A Systematic Review
}

\author{
Ishita Gupta ${ }^{1,}$, Ekta Subhash Chand Sharma ${ }^{2}$ \\ ${ }^{1}$ Infectious Disease Unit, Dubai Health Authority, Dubai, UAE \\ 2 Department of Anesthesia, Dubai Health Authority, Dubai, UAE \\ ${ }^{*}$ Correspondence: ishitagupta1495@gmail.com
}

How to cite this paper: Gupta, I., \& Sharma, E. S. C. (2021). Mucormycosis and Candida Infections in Patients of COVID-19 Pneumonia: A Systematic Review. Global Journal of Epidemiology and Infectious Disease, 81-90. Retrieved from https://www.scipublications.com/journal/index.php/gjeid/article/view/179

Received: October 28, 2021 Accepted: November 28, 2021 Published: November 29, 2021

Copyright: (C) 2021 by the authors. Submitted for possible open access publication under the terms and conditions of the Creative Commons Attribution (CC BY) license (http://creativecommons.org/licenses /by/4.0/).

\begin{abstract}
Introduction: The city of Wuhan in China reported the first case of coronavirus, termed as SARS-CoV-2, in December 2019. To date, 187,827,660 cases have been reported to the WHO (3). With current research focusing on potential therapeutic agents for the coronavirus disease and vaccines, there remain major gaps in our understanding of the pathophysiology and clinical course of this viral pneumonia. Secondary infections are one of them. In this systematic review, we analyze the outcomes of two fungal infections in patients of COVID-19, viz. Mucormycosis and candida. Methodology: A systematic review has been done on secondary infections with mucor and candida fungi in patients of COVID-19. Preferred Reporting Items for Systematic Reviews and Meta-Analysis (PRISMA) guidelines were used. Twenty-three studies were included in the final analysis. Our review included studies from various countries across the globe. The risk of bias was analyzed using the NIH Quality Assessment Tool for Case Series Studies. This study did not require ethical approval as data was obtained from already available databases, and patients were not directly involved. Results: A total of 23 articles were included in the final review and the total number of patients included was 79 Male: female ratio was calculated to be 1.6 and the average age of patients was 52 years (ranging from 24-86 years). Various types of comorbidities were seen in the included patients, the most common being diabetes mellitus. Among the 18 patients in the cohort of mucormycosis, 7 patients died and four studies did not report patient outcomes. Among the 61 patients, 13 patients died and one patient was still ventilated at the time of publication. Conclusion: Secondary infections after COVID-19 are a cause of major concerns. Further studies and case reports are needed to better understand the various other types of secondary infections and also to formulate strategies to prevent these.
\end{abstract}

Keywords: Mucormycosis, Candida, COVID-19, Pneumonia, Systematic Review

\section{Introduction}

The city of Wuhan in China reported the first case of coronavirus, termed as SARSCoV-2, in December 2019 [1]. The World Health Organization (WHO) confirmed the coronavirus outbreak as a worldwide public health emergency on January 30th, 2020, and a pandemic on March 11th, 2020 [2]. Till date 187,827,660 cases have been reported to the WHO [3]. This corresponds to a crude case mortality rate of $4.57 \%$. [4,5]

In recent times, cases of co-infections of COVID-19 and various fungal infections have been reported. Various fungi such as mucormycosis, candida, and aspergillosis have been seen to cause infections in patients affected by coronavirus disease. Even though secondary infections are common complications of viral pneumonia, [6] they increase mortality and increase the burden on the healthcare sector.

These fungal infections can be attributed to the use of corticosteroids in the treatment of COVID-19, patients requiring mechanical/invasive ventilation, high use of empirical 
antibiotics, and patients having other co-morbidities such as diabetes mellitus. [7,8] Currently, the WHO recommends against prescribing antimicrobials in mild to moderate COVID-19 infections without a clear indication of a super-infection. [9]

These co-infections could be due to different pathophysiological reasons. The severe destruction caused to the lung tissues by the coronavirus is a major factor [7]. Other reasons may be the elevated inflammatory markers in the disease and the decreased T-lymphocyte, CD-4, and CD-8 cell count. [7]

With current research focusing on potential therapeutic agents for the coronavirus disease and vaccines, there remain major gaps in our understanding of the pathophysiology and clinical course of this viral pneumonia. Secondary infections are one of them. In this systematic review, we analyze the outcomes of two fungal infections in patients of COVID-19, viz. Mucormycosis and candida.

\section{Methodology}

A systematic review has been done on secondary infections with mucor and candida fungi in patients of COVID-19.

\subsection{Search Method and Strategy}

A systematic search was conducted from COVID-19 inception through June 6th, 2021, for full-length articles focusing on concomitant infections of COVID-19 and two fungal infections (candida and mucormycosis). The search strategy consisted of keywords "Mucormycosis," "SARS-CoV-2," "Candida" and "COVID-19" across the COVID 19 database provided by WHO Global Research Database, CDC COVID-19 Research Articles Downloadable Database, and PubMed database. After a thorough search was performed, fulllength articles meeting the inclusion criteria were evaluated. Subsequently, a manual search of the references of the included articles was accomplished. Preferred Reporting Items for Systematic Reviews and Meta-Analysis (PRISMA) guidelines were used. [10]

The inclusion criteria for the systematic review are as follows:

1. Studies reporting concomitant infection of COVID-19 and fungal infections.

2. Full text, peer-reviewed articles (Meta-analysis, case studies and case series, randomized controlled trials)

The exclusion criteria were as follows:

1. Full texts not available

2. No patient data, laboratory studies, studies done on animal subjects/models

3. Studies pertaining to SARS CoV-1 and MERS

Each study was reviewed by two reviewers independently, and disagreements were resolved via a consensus.

\subsection{Data Collection and Analysis}

Data was collected in the following categories when available:

1. Study design

2. Study country

3. Patient demographics

4. Site of infection

5. Presenting and alarming symptoms

6. Dissemination

7. Treatment

8. Patient outcomes

Our review included studies from various countries across the globe. The studies used have been listed in Table 1.

We tabulated the data using Microsoft Excel. Referencing was done according to guidelines using Endnote. The included data was checked for accuracy by all authors. 
This study did not require ethical approval as data was obtained from already available databases, and patients were not directly involved.

\subsection{Risk of Bias}

Two authors independently assessed the risk of bias of each study included. All disagreements were discussed with all the authors, and the decision was made via a consensus. Non-randomized studies were evaluated using the NIH Quality Assessment Tool for Case Series Studies. [11] Quality assessments were conducted independently, and discrepancies were resolved by consensus.

\section{Results}

\subsection{Search results}

The initial library search identified potentially relevant citations from the WHO Global Research Database, CDC COVID-19 Research Articles Downloadable Database, and PubMed database. It comprised 271 articles. Subsequently, 151 duplicates were removed. A total of 76 articles were excluded after the title and abstract reviews due to not having patient data. The remaining 44 manuscripts were scrutinized further and 21 were further excluded because of unclear evidence and non-relevance to the objective of the review. Thus, twenty-three studies were included in their entirety as shown in Table 1. The PRISMA flow chart is shown in Figure 1.

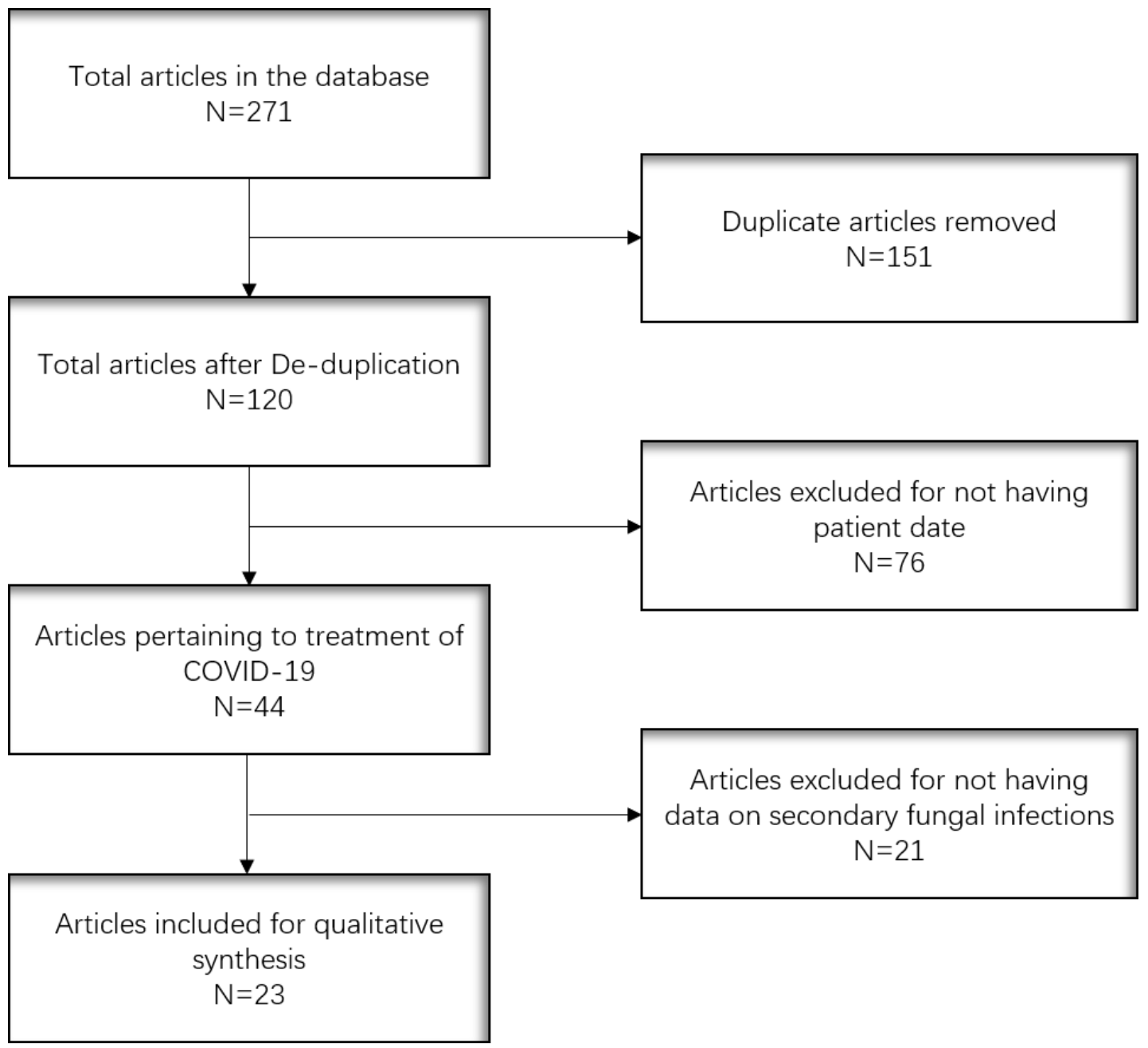

Figure 1. PRISMA flow chart 
Table 1. Summary of the included studies

\begin{tabular}{|c|c|c|}
\hline Name of the Study & DOI & First Author \\
\hline Candida auris outbreak in a COVID-19 specialty care unit-Florida, July-August 2020 & $\underline{10.15585 / \mathrm{mmwr} . \mathrm{mm} 7002 \mathrm{e} 3}$ & Prestel, C. \\
\hline $\begin{array}{l}\text { Role of tocilizumab for concomitant systemic fungal infection in severe COVID-19 pa- } \\
\text { tient }\end{array}$ & 10.1097/MD.0000000000025173 & $\begin{array}{l}\text { Anggraini Permata } \\
\text { Sari }\end{array}$ \\
\hline $\begin{array}{l}\text { Increased incidence of candidemia in a tertiary care hospital with the COVID-19 pan- } \\
\text { demic }\end{array}$ & $\underline{10.1111 / \text { myc. } 13225}$ & Nucci, M. \\
\hline $\begin{array}{l}\text { Epidemiology and Mycology of Candidaemia in non-oncological medical intensive care } \\
\text { unit patients in a tertiary center in the United States: Overall analysis and comparison } \\
\text { between non-COVID-19 and COVID-19 cases }\end{array}$ & $\underline{10.1111 / \text { myc. } 13258}$ & Macauley, P. \\
\hline Post COVID-19 opportunistic candida retinitis: A case report & $\underline{10.4103 / \text { ijo.IJO } 3047 \quad 20}$ & Bhagali, R., \\
\hline $\begin{array}{c}\text { Pulmonary Pathology of COVID-19 Following } 8 \text { Weeks to } 4 \text { Months of Severe Disease: } \\
\text { A Report of Three Cases, Including One With Bilateral Lung Transplantation }\end{array}$ & 10.1093/ajcp/aqaa264 & Aesif, S.W. \\
\hline $\begin{array}{l}\text { Mixed mold infection with Aspergillus fumigatus } \\
\text { and Rhizopus microsporus in a severe acute respiratory syndrome Coronavirus } 2 \\
\text { (SARS-CoV-2) patient }\end{array}$ & 10.1016/j.idnow.2021.01.010 & A.-P. Bellanger \\
\hline Rhinocerebral Mucormycosis and COVID-19 Pneumonia & $\underline{10.14740 / j m c 3637}$ & Alekseyev, K. \\
\hline $\begin{array}{c}\text { Rare and Fatal Gastrointestinal Mucormycosis (Zygomycosis) in a COVID-19 Patient: A } \\
\text { Case Report }\end{array}$ & $\underline{10.5946 / \text { ce.2020.180 }}$ & do Monte Junior ES \\
\hline $\begin{array}{l}\text { Coronavirus disease (Covid-19) associated mucormycosis (CAM): case report and sys- } \\
\text { tematic review of literature }\end{array}$ & $\underline{10.1007 / \mathrm{s} 11046-021-00528-2}$ & Garg, D \\
\hline Pulmonary aspergillosis and mucormycosis in a patient with COVID-19 & 10.1016/j.mmcr.2021.03.006 & Johnson, A.K. \\
\hline A fatal case of Rhizopus azygosporus pneumonia following COVID-19 & $\underline{10.3390 / j o f 7030174}$ & Kanwar, A. \\
\hline Fulminant mucormycosis complicating coronavirus disease 2019 (COVID-19) & 10.1002/alr.22785 & $\begin{array}{l}\text { Karimi-Galougahi, } \\
\text { M. }\end{array}$ \\
\hline $\begin{array}{c}\text { Mucormycosis after Coronavirus disease } 2019 \text { infection in a heart transplant recipient- } \\
\text { case report and review of literature }\end{array}$ & $\underline{10.1016 / j . m y c m e d .2021 .101125}$ & Khatri, A \\
\hline Sino-orbital mucormycosis in a COVID-19 patient: A case report & 10.1016/j.ijscr.2021.105957 & Maini, A. \\
\hline $\begin{array}{l}\text { A challenging complication following SARS-CoV-2 infection: a case of pulmonary mu- } \\
\text { cormycosis. Infection }\end{array}$ & $\underline{10.1007 / \mathrm{s} 15010-020-01561-\mathrm{x}}$ & Pasero, D. \\
\hline $\begin{array}{l}\text { Bronchopleural fistula development in the setting of novel therapies for acute respira- } \\
\text { tory distress syndrome in SARS-CoV-2 pneumonia }\end{array}$ & $\underline{10.1016 / j . r a d c r .2020 .09 .026}$ & Placik, D.A. \\
\hline $\begin{array}{l}\text { COVID-19 triggering mucormycosis in a susceptible patient: a new phenomenon in the } \\
\text { developing world? }\end{array}$ & $\underline{10.1136 / \mathrm{bcr}-2021-241663}$ & Revannavar, S.M. \\
\hline Paranasal Mucormycosis in COVID-19 Patient & $\underline{10.1007 / \mathrm{s} 12070-021-02574-0}$ & Saldanha, M. \\
\hline $\begin{array}{l}\text { Rhino-orbital mucormycosis during steroid therapy in COVID-19 patients: A case re- } \\
\text { port. }\end{array}$ & $\underline{10.1177 / 11206721211009450}$ & Veisi, A. \\
\hline
\end{tabular}




\begin{tabular}{|c|c|c|}
\hline $\begin{array}{l}\text { A case of fatal rhino-orbital mucormycosis associated with new onset diabetic ketoaci- } \\
\text { dosis and COVID-19 }\end{array}$ & $\underline{10.7759 / \text { cureus. } 13163}$ & Waizel-Haiat, S \\
\hline Mucormycosis with orbital compartment syndrome in a patient with COVID-19 & $\underline{10.1016 / j . a j e m .2020 .09 .032}$ & $\begin{array}{l}\text { Werthman-Ehren- } \\
\text { reich, A. }\end{array}$ \\
\hline $\begin{array}{c}\text { The double-edged sword of systemic corticosteroid therapy } \\
\text { in viral pneumonia: A case report and comparative review } \\
\text { of influenza-associated mucormycosis versus COVID-19 } \\
\text { associated mucormycosis }\end{array}$ & $\underline{10.1111 / \text { myc. } 13256}$ & $\underline{\text { Kazem Ahmadikia }}$ \\
\hline
\end{tabular}

\subsection{Study characteristics}

A total of 23 articles [12-34] were included in the final review with six studies $[12,16,23,25,28,31]$ describing candida and the rest describing mucormycosis. The total number of patients included was 79 (61 from the candida infection pool and 18 from mucormycosis). Male: female ratio was calculated to be 1.6 and the average age of patients was 52 years (ranging from 24-86 years). All of the patients included were tested positive for COVID-19 by RT-PCR.

Various types of comorbidities were seen in the included patients, the most common being diabetes mellitus. In the cohort of patients with diabetes, the most commonly found type was Type $2 \mathrm{DM}$, although a few cases of Type $1 \mathrm{DM}$ were also noted. [14,32] Two cases of diabetic ketoacidosis were also seen and reported. [14,33] These two cases were seen in patients diagnosed with mucormycosis. Hypertension, chronic kidney disease, immunosuppression, and cardiac abnormalities were noted in patients of both mucormycosis and candidemia. One patient was a previously diagnosed case of follicular lymphoma [15] and one was a case of CLL [12].

A summary of the demographic features of the patients is included in Table 2.

Table 2. Demographic features of patients.

\begin{tabular}{|c|c|}
\hline Total number of patients & 79 \\
\hline Male: female ratio & 1.6 \\
\hline Average age & 52 years \\
\hline Age range & 24-86 years \\
\hline
\end{tabular}

All of the patients included were tested positive for COVID-19 by RT-PCR

\subsection{Outcomes}

\subsubsection{From the cohort of patients diagnosed with mucormycosis:}

The most common site of presentation of mucormycosis was pulmonary as seen in six out of the 18 total patients.

$[15,18-20,26,27]$ This was followed by rhino-orbital, [21,32,33], sino-orbital, $[24,29,34]$ and rhino-cerebral $[14,30,32]$ presentation with three patients in each group. Fever, malaise, shortness of breath, and cough were the predominant symptoms found in almost all patients. One patient presented with altered mental status [34] and one patient presented 
with left-sided facial pain. [29] A bronchopulmonary fistula was found in one of the patients presenting with pulmonary mucormycosis. [27] Ophthalmoplegia was noted in three of the patients. $[29,30,34]$ The patient with infection in the GI tract had a history of both melena and upper GI bleeding and hence presented with severe anemia. [17] Six patients from the cohort were found to have disseminated infections, [20-22,26,29,32] while others had a localized infection. Eschar formation was also present in five patients. $[14,17,17,21]$ One patient who presented with pulmonary mucormycosis [20] and the patient with cutaneous presentation [22] received convalescent plasma. Nine patients underwent surgical treatment, while one patient underwent an upper GI biopsy for diagnosis. [17] Orbital exoneration had been offered to one of the patients but she refused. [32] Two patients had also received IL-6 inhibitor drugs, [20,27] while another patient had received an interferon-alpha inhibitor. [21] Patients with cutaneous presentation received mycophenolate and tacrolimus. [22] All of the patients received antifungal therapy with two patients receiving it before the diagnosis of mucormycosis $[22,24]$ and the rest after. Among the 18 patients, 7 patients died and four studies did not report patient outcomes.

\subsubsection{Outcomes from the cohort of patients diagnosed with candida:}

Candida infection was found mostly in the bloodstream - seen in 57 out of the 61 patients. [23,25,28,31] Three patients had the infection in their respiratory tract, [12] and one patient presented with features in bilateral eyes. [16] The infection was noted mostly as worsening of clinical and laboratory parameters of COVID. A few patients did not have signs and symptoms of candida, but it was confirmed microbiologically. One patient presented with progressive decreasing vision in bilateral eyes. [16] Three patients from the cohort were found to have disseminated candida infection, [12] while others had a localized infection. The same three patients also received convalescent plasma therapy and underwent surgeries. One of these patients underwent a lung transplant. [12] Anticoagulation was achieved mainly by enoxaparin and dexamethasone was the steroid of choice in most of the patients. 26 out of the 61 patients received antibiotics [12,16,23,31] and two of the patients received anti-fungal treatment. [16,31] Four patients had also received IL6 inhibitor drugs. [12,16,31] Among the 61 patients, 13 patients died and one patient was still ventilated at the time of publication.

\subsubsection{Risk of bias assessment}

Two authors independently assessed the risk of bias for each study included. All disagreements were discussed with all the authors and a decision was made via a consensus. Non-randomized studies were evaluated using the NIH Quality Assessment Tool for Case Series Studies. [11] This is summarized in Table 3. Overall, the risk of bias assessment showed that the included studies had a low to medium risk of bias with every study being of either 'Good' or 'Average' rating.

Table 3. Risk of bias assessment.

\begin{tabular}{|c|c|c|c|c|c|c|c|c|}
\hline & $\begin{array}{c}\text { Was the } \\
\text { study ques- } \\
\text { tion or ob- } \\
\text { jective } \\
\text { clearly } \\
\text { stated? }\end{array}$ & $\begin{array}{c}\text { Was the study } \\
\text { population } \\
\text { clearly and fully } \\
\text { described, in- } \\
\text { cluding a case } \\
\text { definition? }\end{array}$ & $\begin{array}{c}\text { Were } \\
\text { the } \\
\text { cases } \\
\text { con- } \\
\text { secu- } \\
\text { tive? }\end{array}$ & $\begin{array}{c}\text { Were } \\
\text { the sub- } \\
\text { jects } \\
\text { compa- } \\
\text { rable? }\end{array}$ & $\begin{array}{c}\text { Was the } \\
\text { inter- } \\
\text { vention } \\
\text { clearly } \\
\text { de- } \\
\text { scribed? }\end{array}$ & $\begin{array}{c}\text { Were the outcome } \\
\text { measures clearly defined, } \\
\text { valid, reliable, and imple- } \\
\text { mented consistently across } \\
\text { all study participants? }\end{array}$ & $\begin{array}{c}\text { Was the } \\
\text { length of } \\
\text { follow- } \\
\text { up ade- } \\
\text { quate? }\end{array}$ & $\begin{array}{c}\text { Were the } \\
\text { statistical } \\
\text { methods } \\
\text { well-de- } \\
\text { scribed? }\end{array}$ \\
$\begin{array}{c}\text { Were } \\
\text { the re- } \\
\text { sults } \\
\text { well-de- } \\
\text { scribed? }\end{array}$ \\
\hline $\begin{array}{c}\text { 10.1097/MD.000000000 } \\
\text { 0025173 }\end{array}$ & Yes & Yes & N/A & N/A & Yes & Yes & Yes & N/A \\
\hline $\begin{array}{c}10.4103 / \text { ijo.IJO_3047_2 } \\
\text { 0 }\end{array}$ & Yes & Yes & N/A & N/A & Yes & Yes & Yes & N/A \\
\hline
\end{tabular}




\begin{tabular}{|c|c|c|c|c|c|c|c|c|c|}
\hline 10.1111/myc.13258 & Yes & Yes & Yes & Yes & Yes & Yes & No & Yes & Yes \\
\hline 10.1111/myc.13225 & Yes & Yes & Yes & Yes & Yes & Yes & Yes & Yes & Yes \\
\hline $\begin{array}{c}\text { 10.15585/mmwr.mm70 } \\
02 \mathrm{e} 3\end{array}$ & Yes & Yes & Yes & Yes & Yes & Yes & No & No & Yes \\
\hline 10.1093/ajcp/aqaa264 & Yes & Yes & N/A & N/A & Yes & Yes & Yes & N/A & Yes \\
\hline $\begin{array}{c}\text { 10.1007/s12070-021- } \\
02574-0\end{array}$ & Yes & Yes & N/A & N/A & Yes & Yes & Yes & N/A & Yes \\
\hline $\begin{array}{c}10.1007 / \mathrm{s} 15010-020- \\
01561-x\end{array}$ & Yes & Yes & N/A & N/A & Yes & Yes & Yes & N/A & Yes \\
\hline 10.3390/jof7030174 & Yes & Yes & N/A & N/A & Yes & Yes & N/A & N/A & Yes \\
\hline $\begin{array}{c}10.1136 / \mathrm{bcr}-2021- \\
241663\end{array}$ & Yes & Yes & N/A & N/A & Yes & Yes & No & N/A & Yes \\
\hline 10.1111/myc.13256 & Yes & Yes & N/A & N/A & Yes & Yes & No & N/A & Yes \\
\hline 10.5946/ce.2020.180 & Yes & Yes & N/A & N/A & Yes & Yes & N/A & N/A & Yes \\
\hline $\begin{array}{c}\text { 10.1016/j.ajem.2020.09. } \\
032\end{array}$ & Yes & Yes & N/A & N/A & Yes & Yes & N/A & N/A & Yes \\
\hline 10.1002/alr.22785 & Yes & Yes & N/A & N/A & Yes & Yes & No & N/A & Yes \\
\hline $\begin{array}{c}10.1177 / 1120672121100 \\
9450\end{array}$ & Yes & Yes & No & N/A & Yes & Yes & Yes & N/A & Yes \\
\hline 10.7759/cureus.13163 & Yes & Yes & N/A & N/A & Yes & Yes & No & N/A & Yes \\
\hline $\begin{array}{l}\text { 10.1007/s11046-021- } \\
00528-2(0123456789\end{array}$ & Yes & Yes & N/A & N/A & Yes & Yes & Yes & N/A & Yes \\
\hline $\begin{array}{c}\text { 10.1016/j.id- } \\
\text { now.2021.01.010 }\end{array}$ & Yes & Yes & N/A & N/A & Yes & Yes & No & N/A & Yes \\
\hline $\begin{array}{c}\text { 10.1016/j.mmcr.2021.03 } \\
.006\end{array}$ & Yes & Yes & N/A & $\mathrm{N} / \mathrm{A}$ & Yes & Yes & No & N/A & Yes \\
\hline $\begin{array}{c}\text { 10.1016/j.ijscr.2021.105 } \\
957\end{array}$ & Yes & Yes & N/A & N/A & Yes & Yes & No & N/A & Yes \\
\hline $\begin{array}{c}\text { 10.1016/j.radcr.2020.09. } \\
026\end{array}$ & Yes & Yes & N/A & N/A & Yes & Yes & N/A & N/A & Yes \\
\hline $\begin{array}{c}\text { 10.1016/j.my- } \\
\text { cmed.2021.101125 }\end{array}$ & Yes & Yes & N/A & N/A & Yes & Yes & N/A & N/A & Yes \\
\hline 10.14740/jmc3637 & Yes & Yes & $\mathrm{N} / \mathrm{A}$ & N/A & Yes & Yes & Yes & $\mathrm{N} / \mathrm{A}$ & Yes \\
\hline
\end{tabular}




\section{Discussion}

With the increasing use of steroids, and an increase in the hospital stay of COVID-19 patients, secondary infections are being noted much more commonly now. Among these are some fungal infections like mucormycosis, candida infections, aspergillosis, etc. We performed a systematic review about two secondary fungal infections in patients of COVID-19 pneumonia, viz. mucormycosis and candida. Our results showed that both of these infections were seen in many COVID-19 patients and increased ICU admissions and mortality. Almost all of the included patients had one or more comorbidities, the most common being diabetes mellitus and immunosuppression.

It has been known for a long time that viral respiratory tract infections predispose patients to secondary bacterial infections. A commentary by Vaillancourt et. al. published in August 2020 found that $30 \%$ of patients were diagnosed with secondary bacterial infections during the first Sars-CoV outbreak in 2003. [35] COVID-19 is no exception. Many cases from around the world have been identified wherein patients have a worse outcome with superimposed infections. [36] Bengoechea and colleagues [37] and Manna et.al. [38] mentioned various important mechanisms of the molecular pathogenesis of secondary infections in COVID-19. Damage caused by the virus to the respiratory epithelium, the antagonizing of the interferon response by the virus, and effects of the virus on both the adaptive as well as innate immunity could be some important mechanisms. Zang et al in their large cross-sectional study found that nearly $58 \%$ of the included COVID-19 patients developed secondary infections. [39] Another study by Ripa et. al. found secondary infections in $9.3 \%$ of their patients. [40]

Hence, secondary infections should always be considered in patients with worsening clinical and laboratory features. Presenting with alarming symptoms and worsening of COVID, these infections can lead to ICU admissions, mechanical ventilation, and also mortality. Further studies and case reports are needed to better understand the various other types of secondary infections and also to formulate strategies to prevent these.

By comparing the two most commonly found fungal infections in COVID-19 patients, we present a narrative synthesis that brings to light a relatively new but rather important concern. Our review includes studies from across the globe and includes a diverse group of population. Also, the analysis relies on shared subjectivity rather than objectivity so that the results can be generalized to a larger population. However, our study does have limitations. We summarized large amounts of varying information in terms of single numbers and this could ignore essential differences between studies. Also, we saw a significant amount of heterogeneity in our studies which could be due to different geographical locations of the studies, each location having a different set of management guidelines. We were also unable to pool data or run a meta-analysis of our findings due to the vast heterogeneity. The number of patients included in our review is few. Our analysis relied on data from case reports and case series which could have publication biases.

\section{Conclusion}

Secondary infections after COVID-19 are a cause of major concerns. With an increased time of hospitalization of COVID patients and increasing use of steroids, secondary infections should always be considered in patients with worsening clinical and laboratory features. Presenting with alarming symptoms and worsening of COVID, these infections can lead to ICU admissions, mechanical ventilation, and also mortality. Further studies and case reports are needed to better understand the various other types of secondary infections and also to formulate strategies to prevent these.

Conflicts of Interests - The authors declare no conflicts of interests

Ethics approval - An ethical board approval was not required as data was obtained from already available sources and direct patient contact was not present 


\section{Consent to participate - Not applicable}

Consent for publication - The authors consent to publish this work by the journal and transfer all copyrights to the journal and publication house.

Availability of data and material - All data has been included in the manuscript file

Code availability - Not applicable

Author's contribution - Screening: Ishita, Ekta; Data extraction: Ekta, Ishita; Risk of bias assessment: Ishita, Ekta; Data analysis: Ishita; Drafting of the manuscript: Ishita, Ekta

\section{References}

[1] Shah A, Kashyap R, Tosh P, Sampathkumar P, O’Horo JC. Guide to understanding the 2019 novel coronavirus. In: Vol 95. Elsevier; 2020:646-652.

[2] Cucinotta D, Vanelli M. WHO declares COVID-19 a pandemic. Acta Bio Medica Atenei Parm. 2020;91(1):157.

[3] Who China Joint Mission on COVID-19 Final Report. Accessed October 7, 2021. https://www.who.int/docs/default-source/coronaviruse/who-china-jointmission-on-covid-19-final-report

[4] Clarke JM, Majeed A, Beaney T. Measuring the impact of covid-19. BMJ. 2021;373:n1239. doi:10.1136/bmj.n1239

[5] Roser M, Ritchie H, Ortiz-Ospina E, Hasell J. Coronavirus pandemic (COVID-19). Our World Data. Published online 2020.

[6] Zhou P, Liu Z, Chen Y. Bacterial and fungal infections in COVID-19 patients: a matter of concern [published online ahead ofprint April 22, 2020]. Infect Control Hosp Epidemiol.

[7] Gangneux J-P, Bougnoux M-E, Dannaoui E, Cornet M, Zahar J. Invasive fungal diseases during COVID-19: We should be prepared. J Mycol Medicale. 2020;30(2):100971.

[8] Rawson TM, Wilson RC, Holmes A. Understanding the role of bacterial and fungal infection in COVID-19. Clin Microbiol Infect. 2021;27(1):9.

[9] COVID-19 Clinical management: living guidance. Accessed July 15, 2021. https://www.who.int/publications-detail-redirect/WHO-2019-nCoV-clinical-2021-1

[10] Moher D, Liberati A, Tetzlaff J, Altman DG, Prisma Group. Preferred reporting items for systematic reviews and meta-analyses: the PRISMA statement. PLoS Med. 2009;6(7):e1000097.

[11] Study Quality Assessment Tools I NHLBI, NIH. Accessed July 15, 2021. https://www.nhlbi.nih.gov/health-topics/study-qualityassessment-tools

[12] Aesif SW, Bribriesco AC, Yadav R, et al. Pulmonary Pathology of COVID-19 Following 8 Weeks to 4 Months of Severe Disease: A Report of Three Cases, Including One With Bilateral Lung Transplantation. Am J Clin Pathol. 2021;155(4):506-514.

[13] Ahmadikia K, Hashemi SJ, Khodavaisy S, et al. The double-edged sword of systemic corticosteroid therapy in viral pneumonia: A case report and comparative review of influenza-associated mucormycosis versus COVID-19 associated mucormycosis. Mycoses. 2021;n/a(n/a). doi:10.1111/myc.13256

[14] Alekseyev K, Didenko L, Chaudhry B. Rhinocerebral mucormycosis and COVID-19 pneumonia. J Med Cases. 2021;12(3):85.

[15] Bellanger A-P, Navellou J-C, Lepiller Q, et al. Mixed mold infection with Aspergillus fumigatus and Rhizopus microsporus in a severe acute respiratory syndrome Coronavirus 2 (SARS-CoV-2) patient. Infect Dis Now. Published online 2021.

[16] Bhagali R, Prabhudesai NP, Prabhudesai MN. Post COVID-19 opportunistic candida retinitis: A case report. Indian J Ophthalmol. 2021;69(4):987.

[17] do Monte Junior ES, Dos Santos MEL, Ribeiro IB, et al. Rare and fatal gastrointestinal mucormycosis (Zygomycosis) in a COVID19 patient: a case report. Clin Endosc. 2020;53(6):746.

[18] Garg D, Muthu V, Sehgal IS, et al. Coronavirus Disease (Covid-19) Associated Mucormycosis (CAM): Case Report and Systematic Review of Literature. Mycopathologia. 2021;186(2):289-298. doi:10.1007/s11046-021-00528-2

[19] Johnson AK, Ghazarian Z, Cendrowski KD, Persichino JG. Pulmonary aspergillosis and mucormycosis in a patient with COVID-19. Med Mycol Case Rep. 2021;32:64-67. doi:10.1016/j.mmcr.2021.03.006

[20] Kanwar A, Jordan A, Olewiler S, Wehberg K, Cortes M, Jackson BR. A Fatal Case of Rhizopus azygosporus Pneumonia Following COVID-19. J Fungi. 2021;7(3). doi:10.3390/jof7030174

[21] Karimi-Galougahi M, Arastou S, Haseli S. Fulminant mucormycosis complicating coronavirus disease 2019 (COVID-19). Int Forum Allergy Rhinol. 2021;11(6):1029-1030. doi:10.1002/alr.22785

[22] Khatri A, Chang K-M, Berlinrut I, Wallach F. Mucormycosis after Coronavirus disease 2019 infection in a heart transplant recipient - Case report and review of literature. J Med Mycol. 2021;31(2):101125. doi:10.1016/j.mycmed.2021.101125

[23] Macauley P, Epelbaum O. Epidemiology and Mycology of Candidaemia in non-oncological medical intensive care unit patients in a tertiary center in the United States: Overall analysis and comparison between non-COVID-19 and COVID-19 cases. Mycoses . 2021;64(6):634-640.

[24] Maini A, Tomar G, Khanna D, Kini Y, Mehta H, Bhagyasree V. Sino-orbital mucormycosis in a COVID-19 patient: A case report. Int J Surg Case Rep. 2021;82:105957. doi:10.1016/j.ijscr.2021.105957 
[25] Nucci M, Barreiros G, Guimarães LF, Deriquehem VA, Castiñeiras AC, Nouér SA. Increased incidence of candidemia in a tertiary care hospital with the COVID-19 pandemic. Mycoses. 2021;64(2):152-156.

[26] Pasero D, Sanna S, Liperi C, et al. A challenging complication following SARS-CoV-2 infection: a case of pulmonary mucormycosis. Infection. Published online December 17, 2020. doi:10.1007/s15010-020-01561-x

[27] Placik DA, Taylor WL, Wnuk NM. Bronchopleural fistula development in the setting of novel therapies for acute respiratory distress syndrome in SARS-CoV-2 pneumonia. Radiol Case Rep. 2020;15(11):2378-2381. doi:10.1016/j.radcr.2020.09.026

[28] Prestel C, Anderson E, Forsberg K, et al. Candida auris outbreak in a COVID-19 specialty care unit-Florida, July-August 2020. Morb Mortal Wkly Rep. 2021;70(2):56.

[29] Revannavar SM, P S S, Samaga L, V K V. COVID-19 triggering mucormycosis in a susceptible patient: a new phenomenon in the developing world? BMJ Case Rep. 2021;14(4):e241663. doi:10.1136/bcr-2021-241663

[30] Saldanha M, Reddy R, Vincent MJ. Title of the Article: Paranasal Mucormycosis in COVID-19 Patient. Indian J Otolaryngol Head Neck Surg. Published online April 22, 2021. doi:10.1007/s12070-021-02574-0

[31] Sari AP, Darnindro N, Yohanes A, Mokoagow MI. Role of tocilizumab for concomitant systemic fungal infection in severe COVID-19 patient: Case report. Medicine (Baltimore). 2021;100(12):e25173.

[32] Veisi A, Bagheri A, Eshaghi M, Rikhtehgar MH, Rezaei Kanavi M, Farjad R. Rhino-orbital mucormycosis during steroid therapy in COVID-19 patients: A case report. Eur J Ophthalmol. Published online April 10, 2021:11206721211009450. doi:10.1177/11206721211009450

[33] Waizel-Haiat S, Guerrero-Paz JA, Sanchez-Hurtado L, Calleja-Alarcon S, Romero-Gutierrez L. A Case of Fatal Rhino-Orbital Mucormycosis Associated With New Onset Diabetic Ketoacidosis and COVID-19. Cureus. 2021;13(2):e13163-e13163. doi:10.7759/cureus.13163

[34] Werthman-Ehrenreich A. Mucormycosis with orbital compartment syndrome in a patient with COVID-19. Am J Emerg Med. 2021;42:264.e5-264.e8. doi:10.1016/j.ajem.2020.09.032

[35] Vaillancourt Mylene, Jorth Peter. The Unrecognized Threat of Secondary Bacterial Infections with COVID-19. mBio. 11(4):e01806-20. doi:10.1128/mBio.01806-20

[36] Feldman C, Anderson R. The role of co-infections and secondary infections in patients with COVID-19. Pneumonia. 2021;13(1):5. doi:10.1186/s41479-021-00083-w

[37] Bengoechea JA, Bamford CG. SARS-CoV-2, bacterial co-infections, and AMR: the deadly trio in COVID-19? EMBO Mol Med. 2020;12(7):e12560. doi:10.15252/emmm.202012560

[38] Manna S, Baindara P, Mandal SM. Molecular pathogenesis of secondary bacterial infection associated to viral infections including SARS-CoV-2. J Infect Public Health. 2020;13(10):1397-1404. doi:10.1016/j.jiph.2020.07.003

[39] Zhang H, Zhang Y, Wu J, et al. Risks and features of secondary infections in severe and critical ill COVID-19 patients. Emerg Microbes Infect. 2020;9(1):1958-1964. doi:10.1080/22221751.2020.1812437

[40] Ripa M, Galli L, Poli A, et al. Secondary infections in patients hospitalized with COVID-19: incidence and predictive factors. Clin Microbiol Infect. 2021;27(3):451-457. doi:10.1016/j.cmi.2020.10.021 